\title{
Multitemporal Analysis of Coastal Erosion Based on Multisource Satellite Images in the South of the Mono Transboundary Biosphere Reserve in Togo (West Africa)
}

\author{
Yawo Konko1*, Bawinabadi Bagaram², Frédéric Julien³, Kokouvi Gbétey Akpamou, \\ Kouami Kokou ${ }^{5}$ \\ ${ }^{1}$ National Environmental Observatory, National Agency of Environment Management, Lome, Togo \\ ${ }^{2}$ Spatial Optimization Lab, School of Environmental and Forest Sciences, University of Washington, Washington, USA \\ ${ }^{3}$ UPS, INPT, CNRS, EcoLab, Toulouse University, Toulouse, France \\ ${ }^{4}$ Department of Studies and Planning, Ministry of Environment and Forest Resources, Lome, Togo \\ ${ }^{5}$ Laboratory of Forest Research, Faculty of Sciences, University of Lome, Lome, Togo \\ Email: *konkoyawo2@gmail.com
}

How to cite this paper: Konko, Y., Bagaram, B., Julien, F., Akpamou, K.G. and Kokou, K. (2018) Multitemporal Analysis of Coastal Erosion Based on Multisource Satellite Images in the South of the Mono Transboundary Biosphere Reserve in Togo (West Africa). Open Access Library Journal, 5: e4526.

https://doi.org/10.4236/oalib.1104526

Received: March 30, 2018

Accepted: April 25, 2018

Published: April 28, 2018

Copyright ( 2018 by authors and Open Access Library Inc.

This work is licensed under the Creative Commons Attribution International License (CC BY 4.0).

http://creativecommons.org/licenses/by/4.0/

\section{(c) (i) Open Access}

\begin{abstract}
Climate change is affecting terrestrial and maritime ecosystems of Mono transboundary biosphere reserve and the whole Togolese coast. This research focuses both on the dynamics of the barrier beach and on spatial and temporal changes that affected the ocean coastline and its adjacent Lake Togo and Lake Boko during the period 1988-2018. The methodological approach adopted is based on a combination of optical and radar remote sensing. As results, the Lake Togo widened on average by $1.55 \mathrm{~m} /$ year while the coastline of the Lake Boko shrank by $1.25 \mathrm{~m} /$ year. For the coastline of the Ocean, the regression ranged from 1.66 to $5.25 \mathrm{~m} /$ year. The barrier beach experienced an average immersion of $9.25 \mathrm{ha} /$ year. Predictions on the basis of the average rate of immersion of the barrier beach of $9.25 \mathrm{ha} /$ year showed that the latter is exposed to a continuous immersion hazard that would affect more than $7 \%$ of its current area ( $6557.33 \mathrm{ha})$ by the year 2070 .
\end{abstract}

\section{Subject Areas}

Natural Geography, Environmental Sciences

\section{Keywords}

Remote Sensing, Landsat Images, Sentinel Images, Barrier Beach, Lake Togo, Lake Boko 


\section{Introduction}

Climate change is one of the major environmental challenges of 21 st century. In West Africa, the dependence on natural resources by the majority of the population contributes to modifying the ecological equilibrium of many ecosystems [1]. West Africa is one of the areas severely affected by climate change [2]. As consequence, West African coasts experienced several landform changes due to climatic variations, demographic change, and social and economic transformations. The most notable changes are coastal erosions [2] [3].

The Togolese barrier beach is affected by the phenomenon of coastal erosion. Due to its geographic location between the Atlantic Ocean and Lake Togo in the south of the Mono transboundary biosphere reserve, it offers several touristic, economic, cultural, social and scientific services to only name few [4] [5]. For this reason, the barrier beach is privileged and coveted.

Despite all these services, the barrier beach faces many challenges such as urban expansion, elevation of sea level and the flooding of Lake Togo. The intensification of these phenomena weakens the functioning of ecosystems and hinders the conservation and the sustainable management of the barrier beach of the Mono transboundary biosphere reserve. Facing the rapid deterioration of the barrier beach and the exposure of human beings and their assets, there is a need for a strategic planning tool to guide decision makers for next decades. This study, based on the remote sensing, tools, searches for information not only on the dynamics of the barrier beach and its resources, but also on monitoring spatial changes that occurred on the coastline of the Ocean, Lake Togo and Lake Boko which are contiguous.

Tools including spatial remote sensing optical and radar satellite images are the preferred means for discrimination and monitoring of landscape features [6]. They are also the ideal means for forecasting, monitoring and analyzing damages [7] [8].

Consequently, it is sound to seek the contribution of these tools in understanding the barrier beach changes. To that end, a first step will consist of characterizing the landscape of the area, followed by the study of the dynamics of the barrier beach and its resources before studying finally the kinematics of the coastline of the Ocean, Lake Togo and Lake Boko.

\section{Materials and Methods}

\subsection{Study Area}

The transboundary biosphere reserve of the Mono Delta is located in the south of Togo and Benin. It has been officially recognized by the UNESCO "Man and Biosphere" program in 2017 [9]. It helps to insure, through cooperation between concerned countries, the protection and management of transboundary ecosystems. The reserve is characterized by lake, coast, lagoon, swamp and forest areas, with a diversity in species important at national, regional and international levels. 
This study was conducted on the barrier beach of the transboundary biosphere reserve of the Mono Delta, in the Togolese part. It is located between the Atlantic ocean and the Togo lake, between the latitudes $6^{\circ} 10^{\prime} 42.461^{\prime \prime} \mathrm{N}$ and $6^{\circ} 15^{\prime} 12.391 " \mathrm{~N}$ and the longitudes $1^{\circ} 22^{\prime} 24.384^{\prime \prime} \mathrm{E}$ and $1^{\circ} 35^{\prime} 2.837^{\prime \prime} \mathrm{E}$ (Figure 1).

The study area is part of the coastal sedimentary basin of southern Togo which has a Guinean subequatorial climate characterized by four seasons, namely a long dry season from November to mid-March, a long rain season from mid-march to mid-July, a short dry season from August to September and a short rain season from October to November. Precipitations in the area are very irregular, ranging from 1000 to $1400 \mathrm{~mm}$ /year. The hydrographic network is composed mainly of the lagoon system and the Zio and Haho River. The mean temperature is generally high, around $27^{\circ} \mathrm{C}$ [10]. Accumulated sediments in the lagoon zone and the coastline are clays and sea sands. The geology of the coastal sedimentary basin consists of three main aquifer horizons, namely Upper Cretaceous, Paleocene and Continental Terminal aquifers [11] [12]. At the south-east, in the surroundings of the city of Aného, there are some infrastructures installed by the government for protection against coastal erosion. Ecosystems around the lagoon system are severely degraded due to increasing urbanization and human actions. The main economic activities of residents are fishing, agriculture and/or
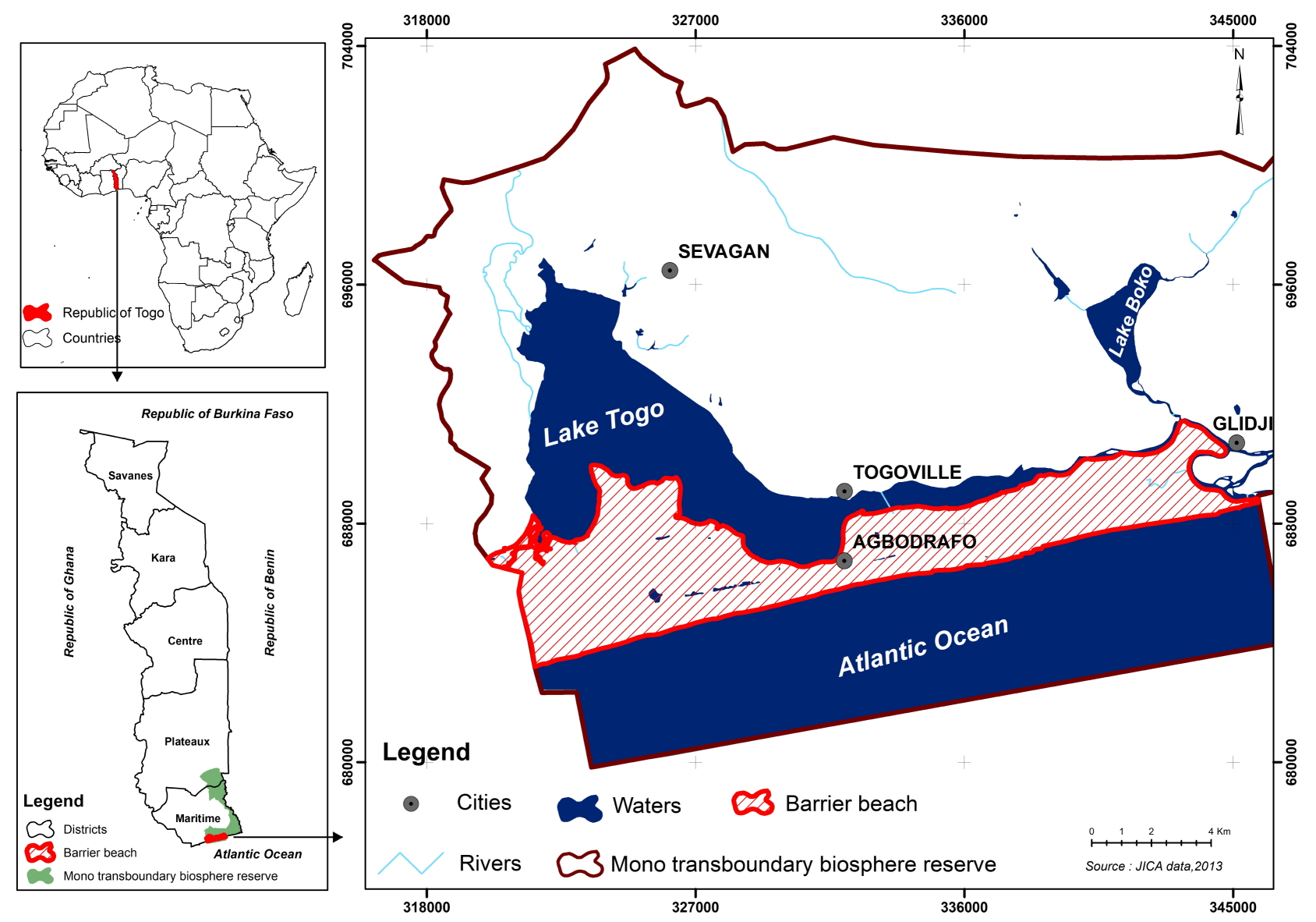

318000
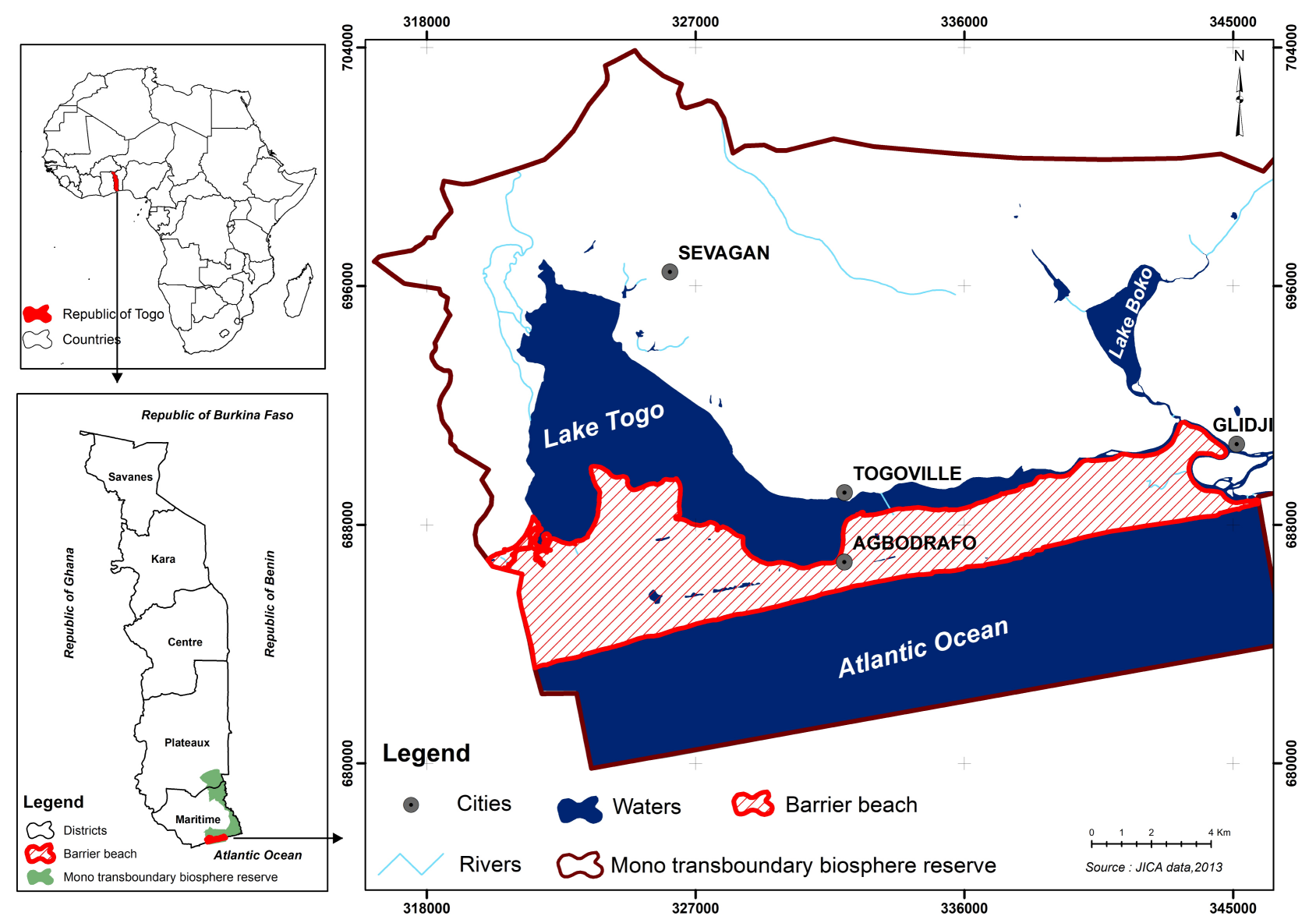

Figure 1. Location of the barrier beach of the Mono transboundary biosphere reserve. 
livestock farming [4]. The population of the barrier beach of the reserve is estimated at 82,724 inhabitants [13].

\subsection{Data Used}

The data used in this study come from optical satellite images (Landsat TM, ETM+, https://landsat.usgs.gov/; Sentinel-2A MSI, https://sentinel.esa.int/) and Radars (Sentinel-1A, https://sentinel.esa.int/). The optical data (Sentinel-2A MSI) were acquired by the Sentinel-2A satellite equipped with Multi Spectral Instrument (MSI) sensor. The MSI measures the Earth's reflected radiance in 13 spectral bands from the visible, near-infrared (VNIR) to shortwave-infrared (SWIR). The Radars data were acquired in rising orbit by the Sentinel-1A satellite equipped with a $C$ band $(\lambda=5.6 \mathrm{~cm})$ sensor in Interferometric Wide Swath (IW) mode at dual-polarization (vertical transmitting with vertical receiving (VV) and vertical transmitting with horizontal receiving $(\mathrm{VH})$ ) and are delivered in GRDH (Ground Range Detected High Resolution) products. The breakdown of images is as follows: TM image of 12 February 1988, ETM+ image of 13 December 2000, MSI image of 04 January 2018 and one IW/GRDH images of 04 December 2017. The dates were chosen in the long dry season in order to use images that were sensed in similar conditions, for a coherent data analysis. TM and ETM+ images were collected on 192/055 (Path/Row) with a spatial resolution of $30 \mathrm{~m}$. MSI images had a spatial resolution ranging from 10 to $60 \mathrm{~m}$ and the Sentinel-1A image had a spatial resolution of about $20 \times 22 \mathrm{~m}^{2}$ in the ground range and azimuth direction, respectively, with an equivalent number of looks (ENL) of 4.9. The pixel size of the radar image is $10 \times 10 \mathrm{~m}^{2}$. The national topographic data provided by the Japanese International Cooperation Agency (JICA) at a scale of 1/50,000 (Sheet NB-31-XIV-1d Hahotoe; Sheet NB-31-XIV-1b Baguida; Sheet NB-31-XIV-2c Aneho) had been used as reference data for georeferencing satellite images.

\subsection{Pre-Processing of Optical Data}

All the optical images have been pre-processed under the SNAP (Sentinel Application Platform) software [14]. Firstly, the optical images were geo-referenced from GPS field surveys and JICA topographic data, under the UTM projection, according to the World Geodetic System, WGS 84, UTM 31North. Subsequently, pretreatments focused on resampling and contrast enhancement operations. The resampling allowed to reduce to $15 \mathrm{~m}$, the spatial resolution of Landsat and Sentinel image bands in order to make their overly possible. The contrast enhancement allowed the rebalancing of color tones and harmonization of histograms of the scenes. The normalized difference water index (NDWI) [15] was used to improve the discrimination of aquatic and terrestrial areas. NDWI is computed according to the Equation (1) where NIR refers to the near infrared band and Green to the Green band. NDWI seeks to maximize reflectance of water using green wave-lengths, minimize the low reflectance of NIR by water features and 
finally, take advantage of the high reflectance of NIR by both the vegetation and the soil. Typically, as results, water has positive values while soil and vegetation have either nil or negative values.

$$
\text { NDWI }=\frac{\text { Green }- \text { NIR }}{\text { Green }+ \text { NIR }}
$$

\subsection{Pre-Processing of Radar Data}

Sentinel-1A images have been processed under the Sentinel 1 software. They underwent operations of geometric correction, radiometric calibration, orthorectification and reduction of speckle. The geometric correction allowed swapping the direction of the images in the north-south direction so that they are in the correct geometry for the operator. The radiometric calibration allowed standardizing the intensity of the signal enabling different images comparison. Orthorectification enabled compliance in WGS 84/UTM ZONE 31 North cartographic projection. The data were orthorectified using the Range Doppler Terrain Correction algorithm [14] and the ASTER (Advanced Spaceborne Thermal Emission and Reflection Radiometer) Digital Terrain Model. This procedure produces orthorectified images with a relative position error of about one pixel [16]. The shimmer known as speckle is a kind of pepper and salt texture noise that degrades the quality of the image and makes interpretation more difficult. The reduction of speckle was performed by averaging the pixel values over a three by three window and replacing the corresponding pixel of the resulting image with the result of the mathematical operation. Complementary images such as images of color composition and images from the report (VV/VH) averaged were also produced to allow easier visual interpretation of terrestrial and aquatic environments.

\subsection{Visual Interpretation of Satellite Images}

It was possible to extract information on the forms of land uses thanks to the Color composition of optical images, NDWI index, VV and VH averaged images, averaged color composition images and the images from the report (VV/VH) at full spatial resolution. The nomenclature used by JICA was adopted with some modification. The different forms of land use were then confirmed by field surveys and Google Earth images. The set of land use units discriminated on optical and radar images allowed the definition of an interpretation key for the classification of optical images.

\subsection{Optical Images Classification}

Firstly, the interpretation key allowed the definition of training zones and the creation of region of interest ROIs (land occupation classes). Subsequently, the supervised classification method with the Support Vector Machine (SVM) algorithm was adopted after statistical computation of means and standard deviations for image bands. This algorithm has been adopted for its efficiency in classifying complex landscapes and producing good results [17]. It also performs 
better compared to many other satellite image classification methods [18] [19]. SVM is a statistical learning classification technique. SVM focuses classification decisions on the boundary between classes and not on mean and variances of classes. After classification, sieving was applied to smooth classes by considering a minimum mapping unit (MMU) of 0.5 ha.

\subsection{Classification Control}

The validation of the classification was carried out through 100 control points randomly selected and distinct from the ROIs at the rate of 20 points per land use class. The control was carried out by field visits. From confrontations of the results with ground truth, the matrix of confusion, the Kappa Indices (K) and also the global precision for the years 1988, 2000 and 2018 were computed. According to the scale of Landis and Koch [20], the classification is said excellent if $\mathrm{K}$ is greater than 0.8 , good if $\mathrm{K}$ is between 0.8 and 0.6 , moderate when $\mathrm{K}$ ranges from 0.6 to 0.2 and bad when $K$ is less than 0.2. Shapefile and area of each landuse/landcover were obtained from the vectorization of the classified images.

\subsection{Spatial-Temporal Dynamics of the Barrier Beach and Its Resources}

Dynamics of the barrier beach landuse units were evaluated through the difference in area $(\Delta S)$ between the second date $\left(D_{2}\right)$ and the first date $\left(D_{1}\right)$ images; and the annual rate of change ( $\left.\mathrm{T}_{\text {annual }}\right)$ in hectare per year was obtained by the Equation (2).

$$
T_{\text {annual }}=\frac{\Delta S}{D_{2}-D_{1}}
$$

\subsection{Shoreline Kinematics}

The shoreline was extracted from the classified images for the years 1988, 2000 and 2018. In order to allow a better visualization of evolutions over time, the coast was subdivided into eight (8) rectangular sectors of about $3 \times 1 \mathrm{~km}$ (Figure 2). Although these sectors do not represent any administrative or natural boundary, they serve for communication, sensitization and decision making. Indeed, it easier to indicate where changes and actions need to be taken thanks to these sectors.

Shoreline kinematics has been automatically evaluated by the dedicated Digital Shoreline Analysis System (DSAS) extension of ArcGIS [21]. The use of DSAS requires the prior integration of shoreline shapefile within a geodatabase and the digitization of an imaginary baseline from which DSAS creates perpendicular transects to the lines to be compared. For this study, 500 transects were created. A conventional step of $50 \mathrm{~m}$ measurements is used between $400 \mathrm{~m}$ long transects. The estimation of the rates of variation of the shoreline is performed following three complementary methods. The first, based on end point rate (EPR), only takes into account two positions of the coastline in time. The EPR is calculated by dividing the distance of shoreline movement by the time elapsed between the oldest and the most recent shoreline. The major advantages of the 


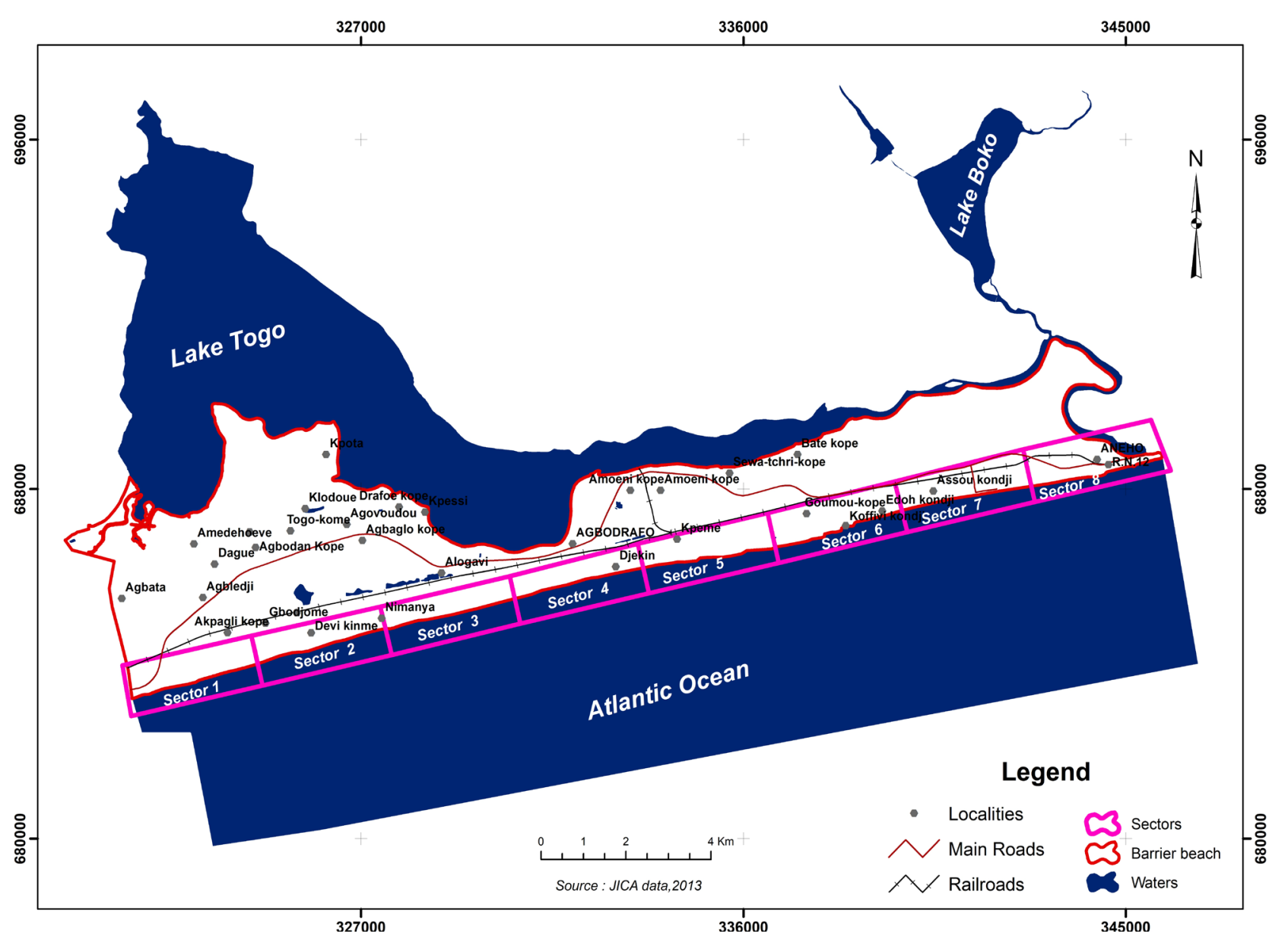

Figure 2. Map of coastline subdivided into eight equal sectors.

EPR are the ease of computation and minimal requirement of only two shoreline dates. The major disadvantage is that in cases where more data are available, the additional information is ignored. Changes in sign (for example, accretion to erosion), magnitude, or cyclical trends may be missed [21] [22]. The second is the linear regression method (LRR) used when data is multiple. A LRR of change statistic is determined by fitting a least-squares regression line to all shoreline points for a particular transects. The regression line is placed so that the sum of the squared residuals (determined by squaring the offset distance of each data point from the regression line and adding the squared residuals together) is minimized. The method of linear regression includes these features: 1) All the data are used, regardless of changes in trend or accuracy; 2) The method is purely computational; 3) The calculation is based on accepted statistical concepts, and 4) the method is easy to employ. It allows highlighting the evolutionary trend over time [3] [21]. The third is the method of net shoreline movements (NSM) over time. It reports the distance between the oldest and youngest shorelines for each transect. This represents the total distance between the oldest and youngest shorelines. It allows calculating the distance lost or recovered by the sea. The surfaces lost or recovered by the sea were also calculated. 


\subsection{Spatial and Temporal Dynamics of Lake Togo and Lake Boko}

Lake Togo and Lake Boko shapefiles were extracted from the classified images for the years 1988, 2000, and 2018. The dynamics was evaluated through the difference in area $(\Delta S)$ between the second date data $\left(D_{2}\right)$ and the first date data $\left(D_{1}\right)$ and the annual rate of change $\left(T_{\text {annual }}\right)$ was calculated according to equation 2. Banks kinematics was evaluated by the Linear Regression Method (LRR) under the DSAS extension.

\section{Results}

The control of the classification of optical images TM, ETM+ gave an overall accuracy of $89.41 \%$ and $88.49 \%$. The Kappa index (K) calculated is 0.86 and 0.87 for the years 1988 and 2000. Control of the classification of the MSI image of 2018 showed that 87 out of the 100 randomly selected points were accurately assigned to their actual landuse. This generated an overall accuracy of $87 \%$ and a Kappa index of $84 \%$ (Table 1).

\subsection{Spatial and Temporal Dynamics of the Barrier Beach and Its Resources}

In 1988, the barrier beach was characterized by five (5) land-use units. These were urban structures and crops (70.45\%), swamps $(25.93 \%)$, cordon of dunes $(2.05 \%)$, body of water $(0.81 \%)$ and the forest $(0.76 \%)$. for the forest class, only one forest has been identified, this is the forest of Asseve.

From 1988 to 2018, the area of urban structures and crops increased while the area of other landuses significantly decreased (Figure 3 and Table 2). The average annual landuse change ranged from -15.60 ha for swamps to 7.84 ha for urbans and crops. As general the global annual change is negative and is about -9.25 ha (Table 2) indicating a reduction of the total area of the barrier beach. Predictions based on the average sinking rate of the barrier beach of $9.25 \mathrm{ha} /$ year showed that it is exposed to a continual risk of immersion which may affect

Table 1. Confusion matrix for estimating the accuracy of the classification.

\begin{tabular}{ccccccc}
\hline $\begin{array}{c}\text { Landuse/ } \\
\text { landcover }\end{array}$ & $\begin{array}{c}\text { Urbans and } \\
\text { crops }\end{array}$ & Swamps & $\begin{array}{c}\text { Cordon } \\
\text { of dunes }\end{array}$ & $\begin{array}{c}\text { Body } \\
\text { of water }\end{array}$ & Forest & Total \\
\hline $\begin{array}{c}\text { Urbans and } \\
\text { crops }\end{array}$ & 18 & 2 & - & - & 2 & 22 \\
$\begin{array}{c}\text { Swamps } \\
\text { Cordon of } \\
\text { dunes }\end{array}$ & 2 & 16 & 3 & 2 & - & 23 \\
$\begin{array}{c}\text { Body of water } \\
\text { Forest }\end{array}$ & - & 2 & 17 & - & - & 19 \\
Total & - & - & - & 18 & - & 18 \\
& 20 & -20 & - & & 18 & 18 \\
& $\quad \begin{array}{c}\text { Overall accuracy }=87 \% \\
\text { Kappa index }=84 \%\end{array}$ \\
\hline
\end{tabular}




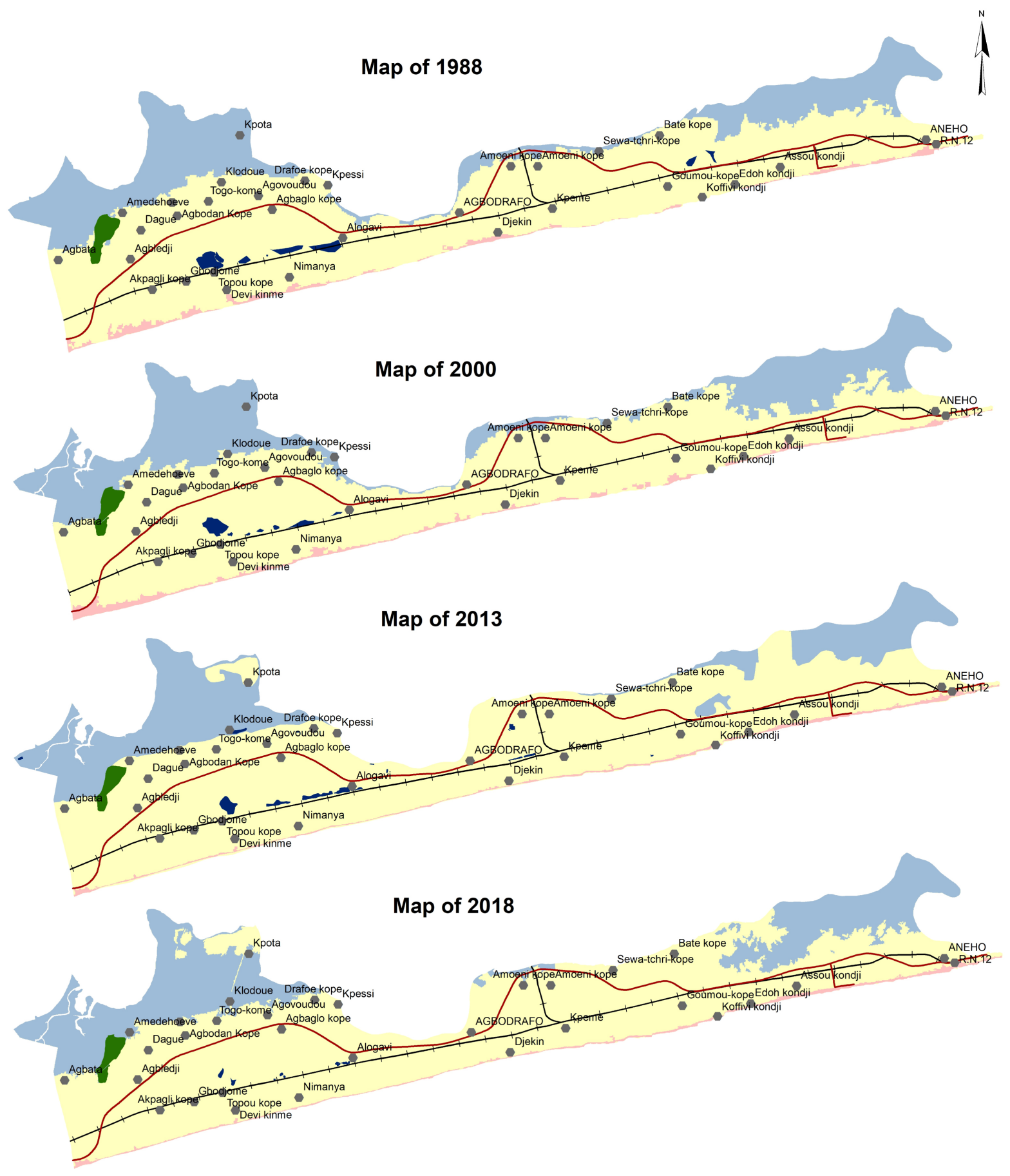

\section{Legend}

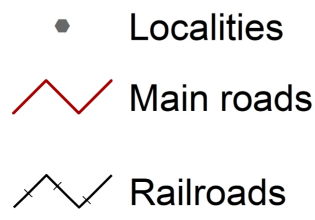

Swamps

Urbans and crops

Body of water

Forest

Cordon of dunes

Figure 3. Land use maps of 1988, 2000, 2013 and 2018. 
Table 2. Change of the landuse/landcover of the barrier beach from 1988 to 2018.

\begin{tabular}{ccccccc}
\hline \multirow{2}{*}{$\begin{array}{c}\text { Landuse/landcover } \\
(\text { LuLc })\end{array}$} & $\begin{array}{c}\text { Area } \\
\text { (ha) }\end{array}$ & $\begin{array}{c}\text { Area } \\
\text { (ha) }\end{array}$ & $\begin{array}{c}\text { Area } \\
\text { (ha) }\end{array}$ & $\begin{array}{c}\text { Area } \\
\text { (ha) }\end{array}$ & $\begin{array}{c}\Delta_{\mathrm{s}} \\
(\mathrm{ha})\end{array}$ & $\begin{array}{c}\mathrm{T}_{\text {annual }} \\
(\text { ha/yr })\end{array}$ \\
\hline Swamps & 1772.44 & 1607.15 & 1502.14 & 13034.53 & -468.91 & -15.60 \\
Body of water & 55.70 & 45.92 & 41.54 & 36.15 & -19.55 & -0.65 \\
Cordon of dunes & 140.08 & 133.67 & - & 127.28 & -12.80 & -0.43 \\
forest & 51.67 & 45.80 & 40.19 & 39.35 & -12.32 & -0.41 \\
Urbans and crops & 4814.94 & 4902.39 & 5007.24 & 5050.02 & 255.08 & 7.84 \\
Total & 6834.83 & 6734.93 & 6591.12 & 6557.33 & -277.50 & -9.25 \\
\hline
\end{tabular}

more than $7 \%$ of its surface area in the 2070 s.

\subsection{Kinematics of the Shoreline}

Analyzes show that over time, the shoreline has changed substantially by sector (Figure 4). These variations are expressed in the first place by erosion phenomena.

An in-depth analysis of changes using the EPR method allowed to draw Table 3. A positive evolution rate means an accretion whereas a negative rate represents an erosion. It follows from Table 3 that the shoreline had generally experienced erosion during all time periods except 2013-2018 in which areas 6, 7 and 8 had experienced accretion phenomena. This period also has a high average erosion rate of up to $8.52 \mathrm{~m} /$ year for sector 1 . For the period 1988-2018, the highest average erosion rates were observed in sectors 1, 2 and 3 with values of $5.29 ; 5.59$ and $4.97 \mathrm{~m}$ /year, respectively.

The assessment of the shoreline changes by LRR method led to similar trends as the assessment by EPR with minor differences. The results for the period 1988-2018 showed that the highest average erosion rate is in sector 2 and is of the order of $5.25 \mathrm{~m} /$ year. On the other hand, the lowest average erosion rate is observed in sector 8 with a value of $1.86 \mathrm{~m} /$ year (Figure 5). The study of shoreline variations by the NSM method showed that sectors 1,2 and 3 are the most affected by the phenomenon. Indeed, from 1988 to 2018, they experienced significant erosion over a distance ranging from $149 \mathrm{~m}$ to $168 \mathrm{~m}$, unlike other sectors where values ranging from $56 \mathrm{~m}$ to $87 \mathrm{~m}$ were recorded (Figure 5).

The area covered by the sea on the shore augmented by 216.6 ha between 1988 and 2018 corresponding to an average annual rate of 7.22 ha (Figure 6). The large losses in area are observed in sectors 1,2 and 3. The average losses are reported on sectors 4 and 7.

\subsection{Spatial-Temporal Dynamics of Lake Togo and Lake Boko}

Lake Togo and Lake Boko have undergone profound changes from 1988 to 2018. Figure 7 illustrates the spatial-temporal change of Lake Togo and Lake Boko.

The statistical analysis of the areas revealed a dynamic evolution of 6.72 

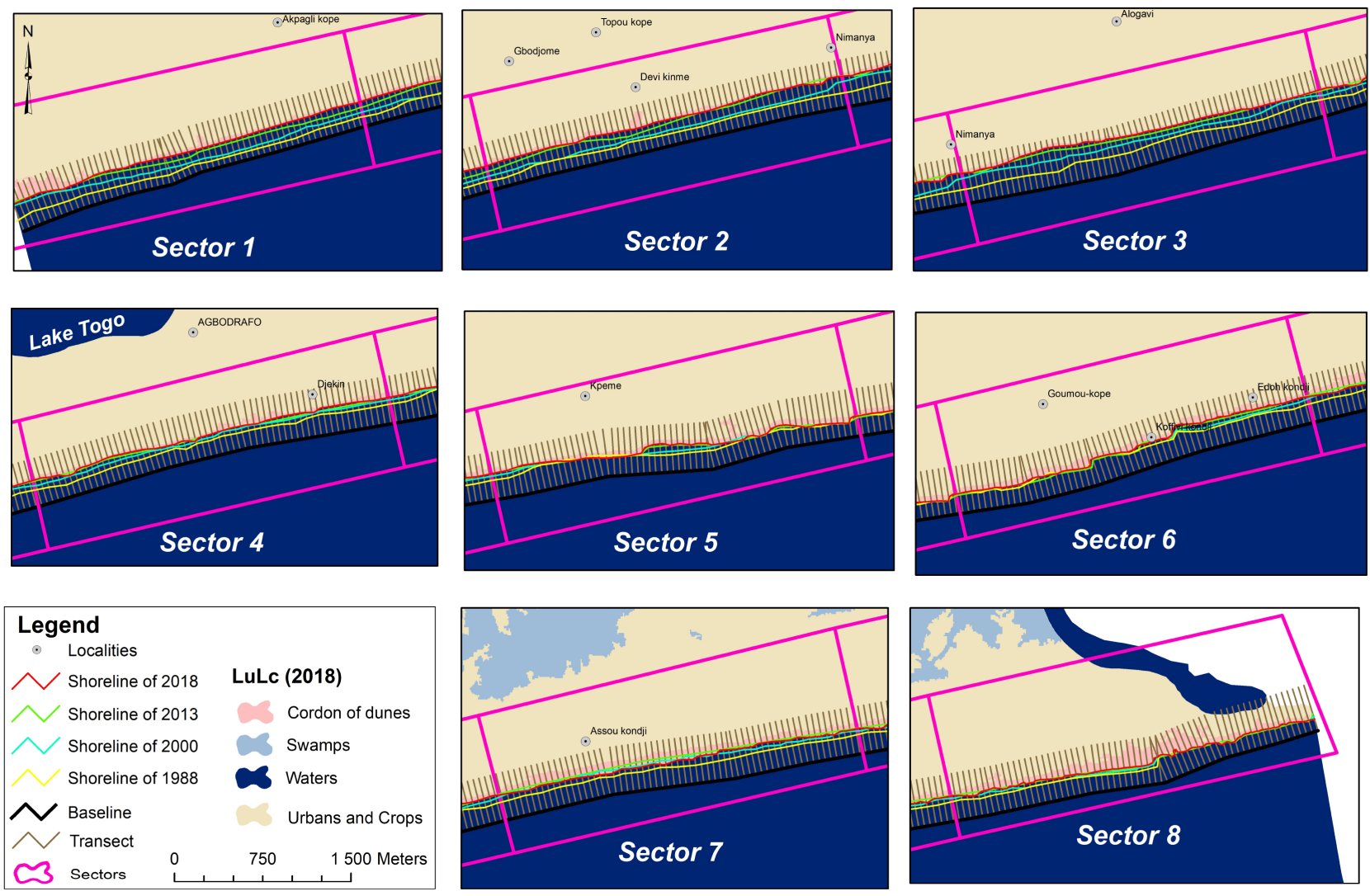

Figure 4. Map of shoreline change over the period 1988 to 2018. The yellow line indicates the position of shoreline in 1988, the blue line its position in 2000, the green line the position in 2013 and the red line the position in 2018.

Table 3. Evolution of the shoreline by the EPR method from 1988 to 2018.

\begin{tabular}{|c|c|c|c|c|c|c|c|c|}
\hline & \multicolumn{8}{|c|}{ Average annual change (meter per years) } \\
\hline & Sector 1 & Sector 2 & Sector 3 & Sector 4 & Sector 5 & Sector 6 & Sector 7 & Sector 8 \\
\hline 1988 to 2000 & -4.35 & -6.01 & -4.89 & -2.92 & -2.09 & -4.87 & -3.75 & -2.75 \\
\hline 2000 to 2013 & -3.01 & -4.24 & -4.81 & -2.83 & -2.16 & -3.98 & -2.91 & -1.91 \\
\hline 2013 to 2018 & -8.52 & -6.51 & -5.21 & -2.92 & -2.21 & 4.88 & 1.09 & 1.09 \\
\hline 1988 to 2018 & -5.29 & -5.59 & -4.97 & -2.89 & -2.15 & -1.99 & -2.52 & -1.86 \\
\hline
\end{tabular}

ha/year for lake Togo and a regressive dynamics of 2.75 ha/year for Lake Boko. There was also a loss in area of 82.35 ha for Lake Boko and a gain of 201.73 ha for Lake Togo over the period 1988-2018. The corresponding average erosion rate for the banks of Lake Togo is $1.55 \mathrm{~m} /$ year. For Lake Boko, the mean accretion rate of the banks is $1.25 \mathrm{~m} /$ year (Table 4). It is important to emphasize that the mutations observed do not occur systematically along the banks but were localized.

\section{Discussions}

The present study was based on multi-source satellite images of different spatial resolutions. Despite the efforts made to improve the visual interpretation of the images, it was found that the $30 \mathrm{~m}$ resolution Landsat TM and ETM + images do 


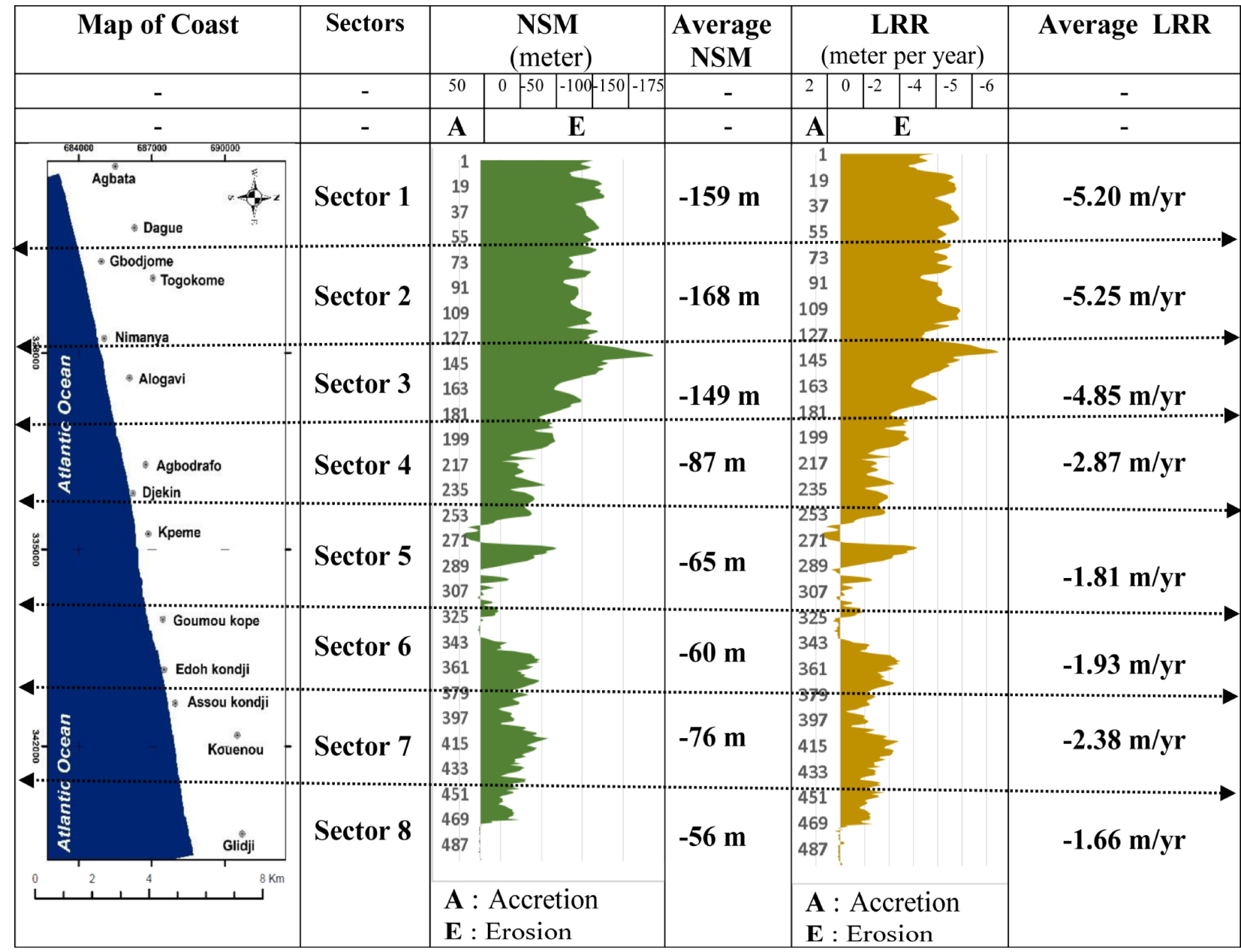

Figure 5. Illustration of shoreline change assessment for the period 1988 to 2018 by NSM and LRR methods.

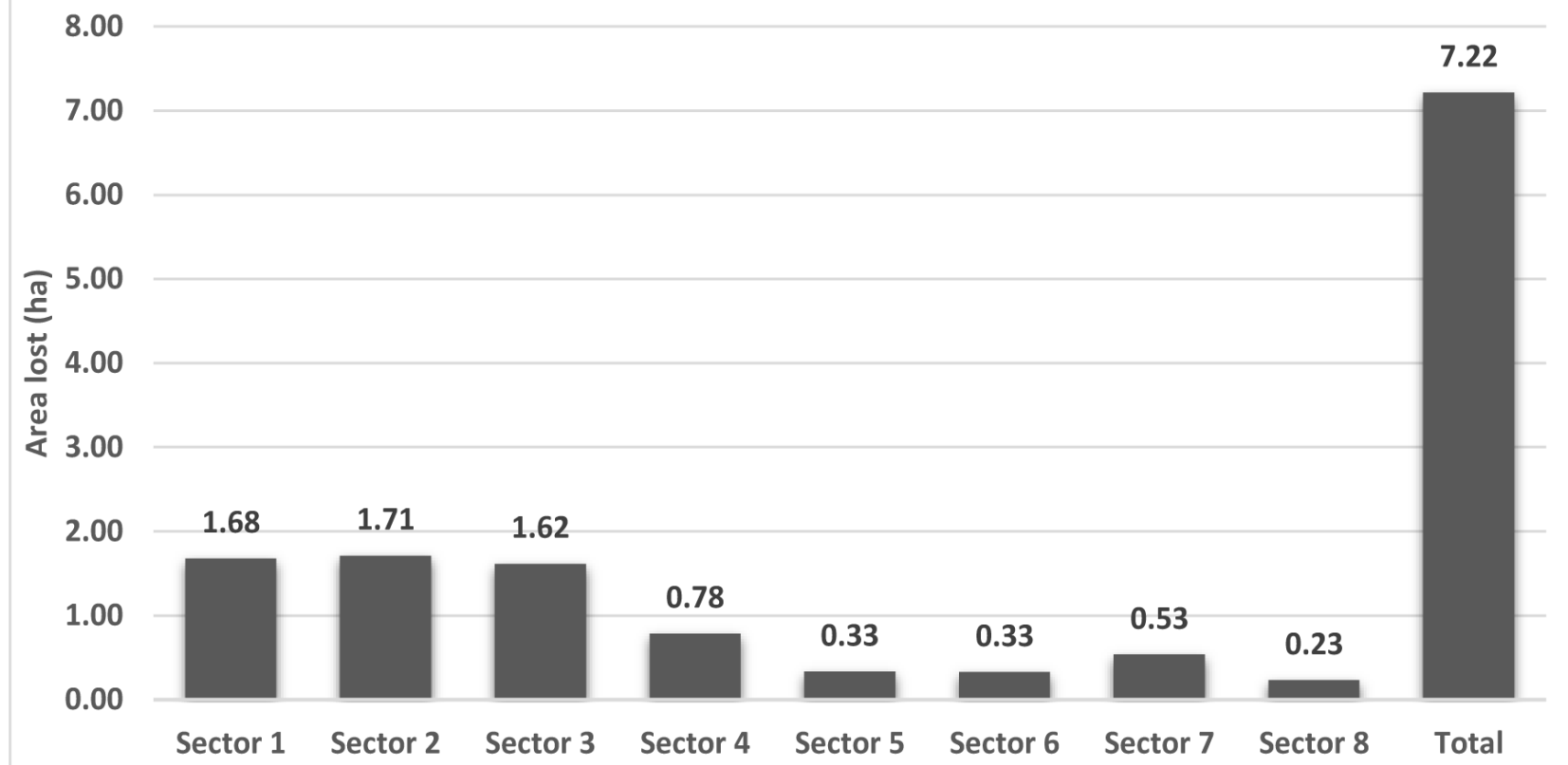

Figure 6. Area submerged annually by coastal erosion. 

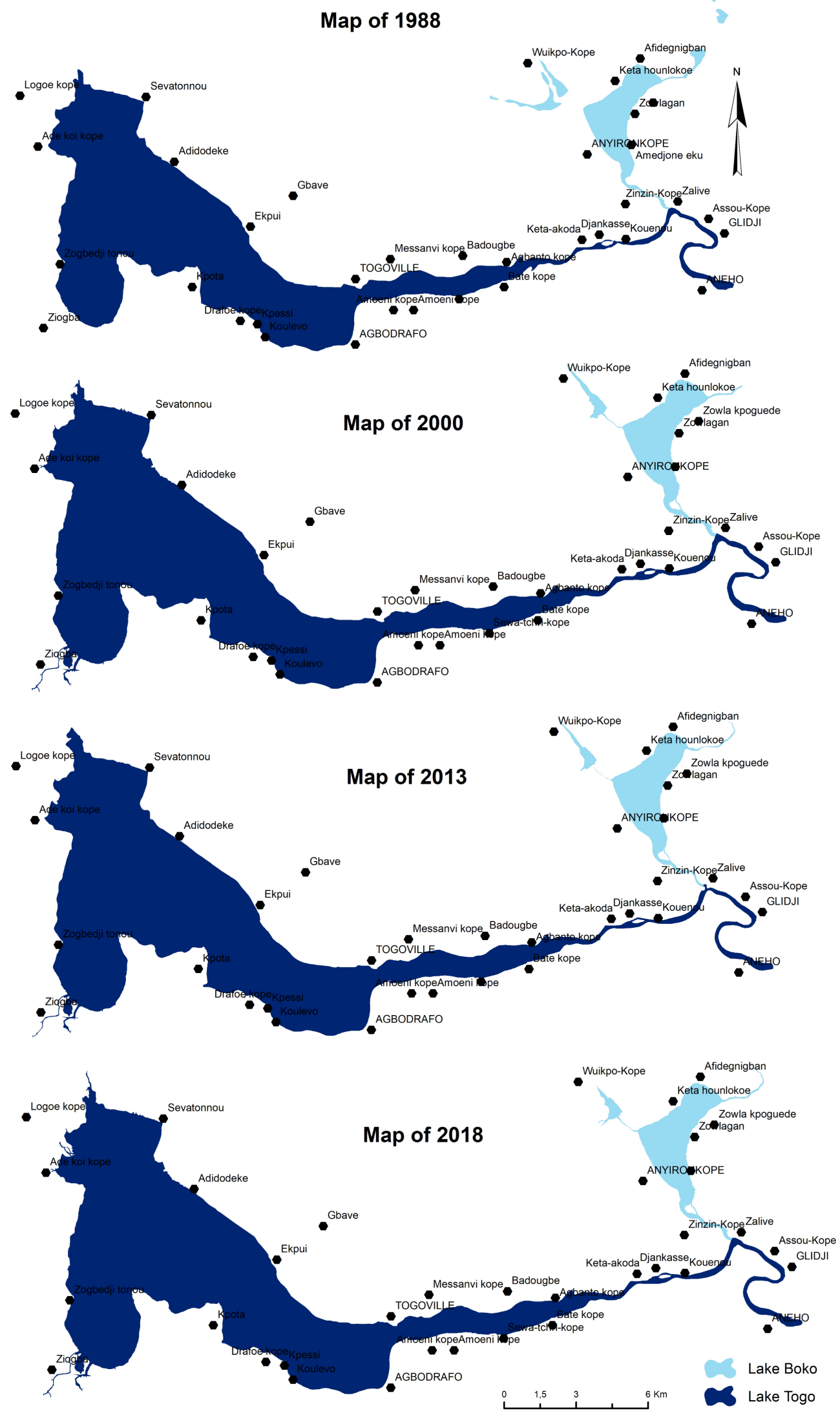

Figure 7. Spatial-temporal change maps of Lake Togo and Lake Boko. 
Table 4. Evolution of the areas of Lake Togo and Lake Boko.

\begin{tabular}{cccccccc}
\hline & 1988 & 2000 & 2013 & 2018 & \multicolumn{3}{c}{1988 to 2018 } \\
\cline { 2 - 8 } & $\begin{array}{c}\text { Area } \\
\text { (ha) }\end{array}$ & $\begin{array}{c}\text { Area } \\
\text { (ha) }\end{array}$ & $\begin{array}{c}\text { Area } \\
(\mathrm{ha})\end{array}$ & $\begin{array}{c}\text { Area } \\
(\mathrm{ha})\end{array}$ & $\begin{array}{c}\Delta_{\mathrm{S}} \\
(\mathrm{ha})\end{array}$ & $\begin{array}{c}\mathrm{T}_{\text {annuel }} \\
(\mathrm{ha} / \mathrm{yr})\end{array}$ & $\begin{array}{c}\text { LRR } \\
(\mathrm{m} / \mathrm{yr})\end{array}$ \\
\hline Lake Togo & 5054.71 & 5151.84 & 5221.55 & 5256.44 & 201.73 & 6.72 & -1.55 \\
Lake Boko & 583.67 & 545.92 & 512.18 & 501.33 & -82.35 & -2.75 & 1.25 \\
\hline
\end{tabular}

not allow for a sufficiently clear and precise distinction of land use units in the same way as Sentinel 2A MSI images of 10 to $60 \mathrm{~m}$ spatial resolution. The MSI sensor has better scene rendering than the ETM and ETM + sensors. On the VV, $\mathrm{VH}$ and $(\mathrm{VV} / \mathrm{VH})$ radar images in full spatial resolution, difficulties were encountered in discriminating the land use units, leading to some confusion. In fact, on full spatial resolution images, the presence of speckles did not make it easy to identify the different classes. On the other hand, on the filtered (averaged) images, the color composition of the images made it possible to distinguish with certainty some land use units with respect to the $\mathrm{VV}, \mathrm{VH}$ and (VV/VH) images in gray level. It appears therefore necessary to combine multisource optical and radar satellite imagery data for a better cartographic performance.

The control of the classification of optical images TM, ETM+ and MSI gave an overall accuracy of $89.41 \%$; 88.49\% and 87\% for the years 1988, 2000 and 2018, respectively and Kappa index $(\mathrm{K})$ calculated was $0.86 ; 0.87$ and 0.84 for the same years, respectively. From the interpretation of the various indices on the basis of the scale of Landis and Koch [20], the classification can be qualified as excellent $(\mathrm{K}>0.8)$ and the results are exploitable. The changes that have occurred over 30 years of identified land use were due to climate changes and human pressure resulting from the population increase and agricultural practices. Indeed, the study area remains one of the densely populated areas of the national territory which leads to overexploitation of land for housing and agricultural practices [23].

The regressive dynamics of $9.25 \mathrm{ha}$ /year observed on the barrier beach remains a concern. The current context of climate change increases exposure of human beings and their structures to immersion and damages. Predictions based on the average sinking rate of the barrier beach of 9.25 ha/year showed that it is exposed to a continual risk of immersion which may affect more than $7 \%$ of its surface area in the 2070s. It is worth highlighting however that this is just a projection from the historical trend and therefore the actual decrease may be higher under worse climatic conditions and/or population practices. The frequency and intensity of extreme natural geomorphic phenomena continue to increase due to climate variability and anthropogenic impact [24] [25] [26] [27]. Hence, various ecosystems of the barrier beach are likely to undergo rapid and massive degradation in the near future, which may lead to their reduction or even their complete depletion. As consequence, the flora and fauna richness as well as the local population estimated at 82,724 inhabitants [13] and basic infrastructures of the area 
will be affected. The immersion of the barrier beach will also lead to the reduction of the national surface area with all the consequences.

Analysis of the rates of change in the shoreline using the end point rate (EPR) method and the linear regression method (LRR) underscored that LRR method underestimated the rates of change compared to the EPR method. This finding is in accordance with several authors who stated LRR method is the most efficient and the easiest to use [3] [21] [22]. Indeed, this method based on universal statistical concepts, takes into account all the positions of the coastline in time, unlike the EPR method which neglects changes between two chosen dates. However, the EPR method has the advantage of giving the evolution of the coastline by period tranche unlike the LRR method which gives the evolution over the period.

The $1.55 \mathrm{~m}$ yearly expansion on average of the lake Togo can be explained by sediment input from the Zio River located upstream. This phenomenon leads to siltation and gradual expansion of the lake Togo. In fact, the ASTER DEM data of the area helped identify a decreasing slope from the Zio River to the Togo Lake and a flow in the North-South direction. The $1.25 \mathrm{~m}$ yearly shrinkage of the lake Boko on average could also be explained by the fact that the latter is not in connection with a proper river upstream and loses its volume of water by pouring into Lake Togo due to altitude gradient.

The regression ranging from 1.66 to $5.25 \mathrm{~m} /$ year (LRR method) observed on the Togolese coastline is lower than the results of Blivi [28] and Blivi and Adjoussi [29] which showed a regression of the coastline ranging from 5 to 10 $\mathrm{m} /$ year. This discrepancy could be explained by differences in the methodological approach. In fact, in this study the coastline was extracted by supervised classification of satellite images (Landsat TM, ETM+ and Sentinel-2A MSI) and the kinematics was evaluated using the statistical methods available in the DSAS extension whereas, Blivi and Adjoussi (2004) proceeded by means of a Landsat image analysis (MSS and TM) and the methods of coastline extraction and calculation of the kinematics were not clearly defined. Divergences are also related to the construction by the government over the last decade, of protection infrastructure at certain parts of the coastline to mitigate coastal erosion. In fact, the protection infrastructures have a positive effect and are highly recommended.

The regression of the coastline observed in this study resulted in the loss of 216.6 ha of land area over the period 1988-2018. At this pace, the country will lose more than 570 ha of its area by 2070 if no concrete action is taken.

The results obtained are also similar to several studies conducted in West Africa showing a reduction of the coastal area [2] [30] [31] [32] [33].

\section{Conclusion}

This study has contributed to spatial-temporal monitoring of 1) the barrier beach and its resources, 2) Lake Togo and Lake Boko and 3) the coastline of the littoral. The results showed that the barrier beach experienced an immersion of 
$9.25 \mathrm{ha} /$ year in favor of Lake Togo and the ocean. Lake Togo is expanding by $1.55 \mathrm{~m}$ /year while Lake Boko is shrinking by $1.25 \mathrm{~m} /$ year. The shoreline experienced an average recession ranging from 1.66 to $5.25 \mathrm{~m} /$ year. Predictions based on the average rate of immersion of the barrier beach of 9.25 ha/year showed that it is exposed to a continual risk of immersion which may affect more than $7 \%$ of its surface area by the 2070s. The different spatial changes observed could be attributed to natural phenomena (climate changes) and human activities. The results obtained will serve as decision support tools for the design and implementation of appropriate management plans.

\section{Acknowledgements}

We thank the three reviewers that contributed in the improvement of the earlier version of this document. We thank as well the NGO APEDD-Togo that gave us their support for the field data collection.

\section{References}

[1] Bani, S.S. and Yonkeu, S. (2016) Flood Risks in the City of Ouagadougou: Mapping of Risk Areas and Prevention Measures. Journal Ouest-Africain des Sciences de Gestion, 1, 1-109.

[2] Faye, I. (2010) Coastline Dynamics on Sandy Coasts from Mauritania to Guinea-Bissau (West Africa): Regional and Local Approaches by Photo-Interpretation, Image Processing and Analysis of Old Maps. PhD Thesis, University of Western Brittany, France.

[3] Djagoua, E.M., Bakayoko, F., Kouadio, M.J., Kassi, A.J.B. and Mobio, A.B.H. (2016) Cartography of Coastal Dynamics in Grand-Lahou: Tool Use Digital Shoreline Analysis System (Dsas). European Scientific Journal, 12, 327-335. https://doi.org/10.19044/esj.2016.v12n36p327

[4] Atanle, K., Bawa, L.M., Kokou, K., Djaneye-Boundjou, G. and Edorh, M.T. ( 2013) Seasonal Distribution of Phytoplankton According to the Physicochemical Characteristics of Lake Zowla (Lake Boko) in Southeast Togo: The Case of the Dry Season and the Long Dry Season. Journal of Applied Biosciences, 64, 4847-4857. https://doi.org/10.4314/jab.v64i1.88474

[5] Bruce, A.K., Sama, S. and Kokou, K. (2015) Identification of Environmental Changes and Land Use in the Lagoon Ecosystems of Togo Southeastern. Open Access Library Journal, 2, e1895. https://doi.org/10.4236/oalib.1101895

[6] Konko, Y. (2016) Contribution of Remote Sensing and GIS to the Integrated Management of Community Forest Resources in the Bas-Mono Valley (South-East Togo). Master's Thesis, Post University Regional School of Integrated Management of Tropical Forests and Territories, Kinshasa, Democratic Republic of Congo.

[7] Kerle, N. and Oppenheimer, C. (2002) Satellite Remote Sensing as a Tool in Lahar Disaster Management. Disasters, 26, 140-160. https://doi.org/10.1111/1467-7717.00197

[8] Domenikiotis, C., Loukas, A. and Dalezios, N.R. (2003) The Use of NOAA/AVHRR Satellite Data for Monitoring and Assessment of Forest Fires and Floods. Natural Hazards and Earth System Sciences, 3, 115-128. https://doi.org/10.5194/nhess-3-115-2003

[9] UNESCO (2017) 
http://www.unesco.org/new/en/natural-sciences/environment/ecologicalsciences/bi osphere-reserves/africa/benintogo/mono/

[10] MERF (2011) National Forest Action Plan of Togo, Phase 1 (PAFN 1-TOGO) 2011-2019.

[11] Johnson, A.K.C. (1987) The Coastal Phosphate Basin of Togo (Maestrichtien-Eocene). Doctoral Thesis, University of Bourgogne (France) and University of Benin (Togo).

[12] Costa, D.P. (2005) Biostratigraphy and Palaeogeography of the Sedimentary Basin of Togo. Doctoral Thesis, University of Lome, Togo.

[13] INSEED (2010) Result of the Fourth General Census of Population and Habitat.

[14] Brockmann, C. (2017) SNAP Software, Array Systems Computing and C-S. http://www.step.esa.int/main/toolboxes/snap/\#

[15] Mcfeeters, S.K. (1996) The Use of the Normalized Difference Water Index (NDWI) in the Delineation of Open Water Features. International Journal of Remote Sensing, 17, 1425-1432. https://doi.org/10.1080/01431169608948714

[16] Cazals, C., Rapinel, S., Frison, P.L., Bonis, A., Mercier, G., Mallet, C., Corgne, S. and Rudant, J.P. (2016) Mapping and Characterization of Hydrological Dynamics in a Coastal Marsh using High Temporal Resolution Sentinel-1A Images. Remote Sensing, 8, 570. https://doi.org/10.3390/rs8070570

[17] Noumonvi, K.D., Mounir, F. and Belghazi, B. (2017) Spatial Multi-Criteria Based Analysis to Assess Dynamics and Vulnerability of Forest Ecosystems to Global Changes: Case of Maamora Forest-Morocco. Open Access Library Journal, 4, e3889. https://doi.org/10.4236/oalib.1103889

[18] Shao, Y. and Lunetta, R.S. (2012) Comparison of Support Vector Machine, Neural Network and CART Algorithms for the Land-Cover Classification using Limited Training Data Points. Photogrammetry and Remote Sensing, 70, 78-87. https://doi.org/10.1016/j.isprsjprs.2012.04.001

[19] McNairn, H., Champagne, C., Shang J., Holmstrom, S. and Reichert, G. (2009) Integration of Optical and Synthetic Aperture Radar (SAR) Imagery for Delivering Operational Annual Crop Inventories. Photogrammetry and Remote Sensing, 64, 434-449. https://doi.org/10.1016/j.isprsjprs.2008.07.006

[20] Landis, J.R. and Koch, G.G. (1977) The Measurement of Observer Agreement for Categorical Data. Biometrics, 33, 159-174. https://doi.org/10.2307/2529310

[21] Thieler, E.R., Himmelstoss, E.A., Zichichi, J.L. and Ergul, A. (2017) Digital Shoreline Analysis System (DSAS) Version 4.4, An ArcGIS Extension for Calculating Shoreline Change, US Geological Survey Open-File Report 2008-1278. https://pubs.er.usgs.gov/publication/ofr20081278/\#

[22] Dolan, R., Fenster, M.S. and Holme, S.J. (1991) Temporal Analysis of Shoreline Recession and Accretion. Journal of Coastal Research, 7, 723-744.

[23] Kpedenou, K.D., Ahe, P. and Boukpessi, T. (2016) Spatio-Temporal Dynamics of Land Use/Land Cover in Southeastern Togo: Mapping Test using Spatial Remote Sensing. Ahoho Journal, 16, 131-143.

[24] Ashley, S.T. and Ashley, W.S. (2008) Flood Fatalities in the United States. Journal of Applied Meteorology and Climatology, 47, 806-818. https://doi.org/10.1175/2007JAMC1611.1

[25] Hong, Y., Adhikari, P. and Gourley, J.J. (2012) Flash Flood. In: Bobrowsky, P., Ed., Encyclopedia of Natural Hazards, Springer, Dordrecht, 324.

[26] Calianno, M., Ruin, I. and Gourley, J.J. (2012) Supplementing Flash Flood Reports with Impact Classifications. Journal of Hydrology, 477, 1-16. 
https://doi.org/10.1016/j.jhydrol.2012.09.036

[27] Darwish, K., Smith, S.E., Torab, M., Monsef, H. and Hussein, O. (2017) Geomorphological Changes along the Nile Delta Coastline between 1945 and 2015 Detected using Satellite Remote Sensing and GIS. Journal of Coastal Research, 33, 786-794. https://doi.org/10.2112/JCOASTRES-D-16-00056.1

[28] Blivi, A. (2001) Impact of Coastal Erosion and Elements of Vulnerability Study: Example from Togo (Gulf of Guinea). Journal of the University of Moncton, 32, 289-308.

[29] Blivi, A. and Adjoussi, P. (2004) The Kinematics of the Coastline in Togo Seen by Remote Sensing. Geo-Eco-Trop, 28, 27-38.

[30] Tano, R.A., Aman, A., Kouadio, K.Y., Toualy, E., Ali, K.E. and Assamoi, P. (2016) Assessment of the Ivorian Coastal Vulnerability. Journal of Coastal Research, 32, 1495-1503. https://doi.org/10.2112/JCOASTRES-D-15-00228.1

[31] Degbe, C.G., Sohou, Z., Oyede, L., Adje, C., Du penhoat, Y., Bourles, B., Chuchla, R. and Almar, R. (2017) Evolution of the Coastline of the Beninese Coast from 2011 to 2014. CAMES Journal, 5, 21-28.

[32] Evadzi, P.I.K., Zorita, E. and Hünicke, B. (2017) Quantifying and Predicting the Contribution of Sea-Level Rise to Shoreline Change in Ghana: Information for Coastal Adaptation Strategies. Journal of Coastal Research, 33, 1283-1291. https://doi.org/10.2112/JCOASTRES-D-16-00119.1

[33] Bakhoum, P.W., Ndour, A., Niang, I., Sambou, B., Traore, V.B., Diaw, A.T., Sambou, H. and Ndiaye, M.L. (2017) Coastline Mobility of Goree Island (Senegal) from 1942 to 2011. Marine Science, 7, 1-9. 